\title{
Craig, Todd. "''Jackin' for Beats'": DJing for Citation Critique." Radical Teacher [Online], 97 (2013): 20-29. Web. 19 Feb. 2014
}

Radical Teacher wishes to apologize to Todd Craig for misprinting the title of his article in RT 97 (Hip Hop and Critical Pedagogy). Instead of "'Jackin' for Beats'": DJing for Citation Critique, the title should have been "Jackin' for Beats": DJing for Citation Critique. 